\title{
Partial Discharge Comprehensive Fault Decision of 0.4KV/10KV Power Transformer Based on PSD-PSO Algorithm
}

\author{
Shao Zhenhua ${ }^{1, *}$, Guo Yanyan ${ }^{1}$, Chen Tianxiang ${ }^{1}$, Chen Li-an ${ }^{1}$ and Zheng Mei-rong ${ }^{2}$ \\ ${ }^{I}$ Department of Electrical Engineering and Automation Xiamen University of Technology, Xiamen Fujian, 361024, \\ China \\ ${ }^{2}$ Fujian Province Electric Power Maintenance Company, Xiamen Fujian, 361000, China
}

\begin{abstract}
In order to ensure the stability of power grid, $0.4 \mathrm{kV} / 10 \mathrm{kV}$ power transformer PD on-line monitoring system is studied in this paper. With the help of pulse current detection method, the PD propagation characteristics can be precisely located by the power spectrum density (PSD). In order to have a good weight distribution of PSO and the statistical analysis problem, PSD-PSO algorithm is introduced in this paper. And the comprehensive fault decision based on PSD- PSO algorithm is studied in this paper. At last the simulation results show that the proposed method can improve the accuracy and the real- time performance of fault diagnosis via power transformer.
\end{abstract}

Keywords: $0.4 \mathrm{KV} / 10 \mathrm{KV}$ power transformer, comprehensive fault decision, partial discharge, particle swarm optimization (PSO), power spectrum density (PSD).

\section{INTRODUCTION}

As an important part of transmission and distribution equipment, power transformers play important roles in power grid. Moreover, the overall deterioration of insulation level of power transformers is an important reference index for stable running and economic operation of a power system .In view of the present situation that the periodical inspection and repair cycle cannot perform the inspection and repair scientifically and reasonably, the insulation level of power transformers cannot be kept stable during the long-term online operation. In order to ensure the stability of power grid, it is indispensable to reinforce the monitor and diagnosis of the transformer insulation. Partial discharge (PD) during insulation is considered as a major cause of insulation degradation in transformers attaching importance due to the safety and reliability of running transformers. Many researchers pay much more attention to the study of fault diagnosis of power transformers [1-4].

With the fast development of sensing technology, computer technology and information processing technology, modelling analyzing and knowledge reasoning based on Rough set and ANN network have been studied [5-7], esp. comprehensive application of internal fault diagnosis technology of transformer has been applied in industries [8,9]. ANN network, expect system and fuzzy set theory etc. play a promising role in condition monitoring and fault diagnosis in power grid equipments. In order to deal with weight distribution of PSO and the statistical analysis problem, the comprehensive fault decision based on PSD-PSO algorithm

\footnotetext{
*Address correspondence to these authors at the Department of Electrical Engineering and Automation Xiamen University of Technology, Xiamen Fujian, 361024, China; Tel: +8618359224182; E-mail: Szh4h@163.com
}

is studied in this paper. According to the problems existed in field $0.4 \mathrm{kV} / 10 \mathrm{kV}$ power transformer PD on-line monitoring system, this paper researches on the PD propagation characteristics based on the detection method of pulse current method (PCM).

\section{PD TEST AND PROPAGATION CHARACTER- ISTICS DETECTION METHODS}

Auto-recognition to discharge types in on-line PD monitoring system could be used to find out internal partial defects and the relevant discharge development degree in time, and thus the equipment is prevented from the coming faults. In general, electromagnetic radiation, high frequency pulse, dielectric loss voice, lighting and heating emission can be monitored with the profile of PD in power equipments. And there are several PD propagation characteristics methods discussed earlier. Electric and non-electric methods are to diagnose and correct the problem situations for large power transformer, such as pulse current method (PCM), dielectric loss method (DLM) and electromagnetic radiation method (ERM) have been studied in the past decade. According the IEC standards, PCM is the recommended detection method for PD propagation characteristics.

\subsection{PD Models and Experimental Devices}

According to the internal insulation PD in the transformer and the PD propagation characteristics, there are three PD models designed in this paper, which are shown in Fig. (1), namely point discharge in transformer oil (P1), solid Insulation of power transformer ( $\mathrm{P} 2)$, and surface discharge in transformer oil (P3). The PD signals are measured by PCM. Test PD detection schematic diagram and experimental devices are shown in Figs. (2) and (3). 

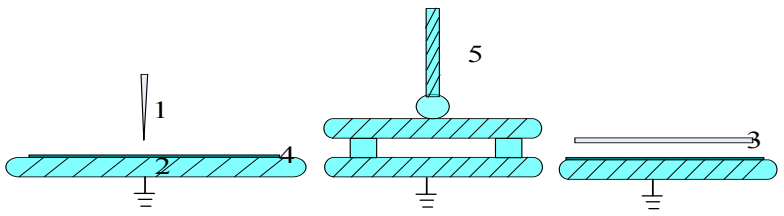

point discharge in transformer oil (P1)

Solid Insulation of Power Transformer (P2)

surface discharge in transformer oil (P3)

1 needle electrode 2 circular plate electrode 3 plate electrode 4 tank oil 5 ball electrode

Fig. (1). PD models of artificial defects.

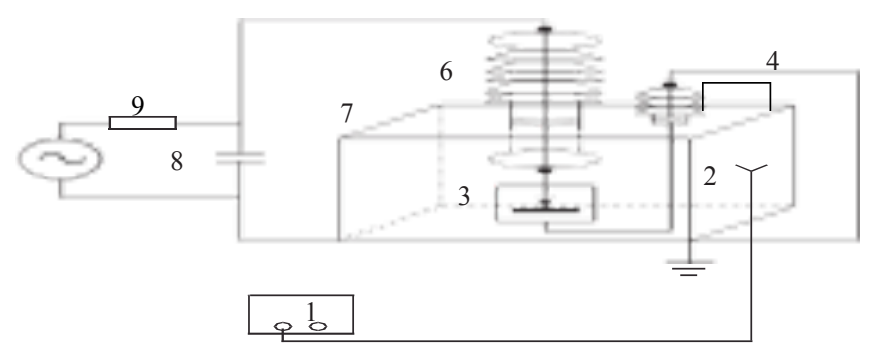

1 PD detection instrument (IFD251) 2 High frequency Antenna 3 Electrode 4 Ground wire $50.4 \mathrm{kV}$ Insulating casing $610 \mathrm{kV}$ Insulating casing 7 Transformer oil tank 8 Coupling capacitance 9 Protection resistors.

Internal schematic diagram of $10 \mathrm{KV} / 400 \mathrm{~V}$ power transformer by AUTOCAD

Fig. (2). The ammonia storage capacity of catalyst.

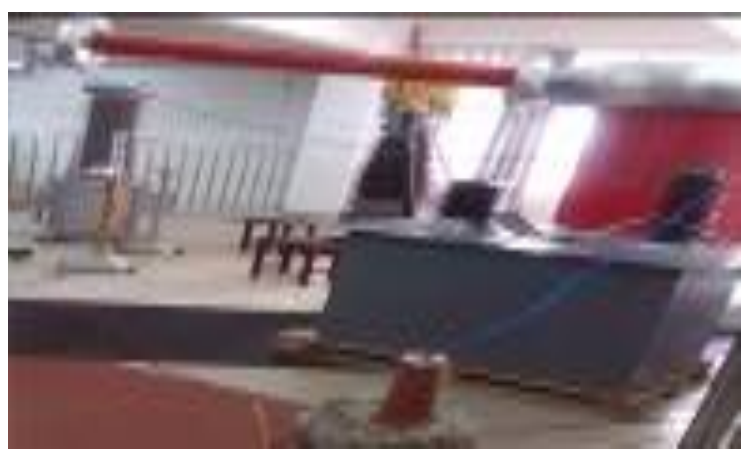

Fig. (3). Experimental devices on $0.4 \mathrm{kV} / 10 \mathrm{kV}$ power transformer PD detection.

\subsection{Experimental Procedure and Starting Discharge Voltage VS Extinction Voltage Mode}

In order to have a good contrast effect, starting discharge voltage vs. extinction voltage mode are studied in this experiment. With the study of point discharge in transformer oil the source voltage is gradually increased from 3.0 to $5.8 \mathrm{kV}$ by $0.2 \mathrm{kV}$ step and the PD distance is gradually increased from $0.5 \mathrm{~cm}$ to $3.5 \mathrm{~cm}$. On the other hand, with the study of surface discharge in transformer oil, the source voltage is gradually increased from 6.3 to $7.3 \mathrm{kV}$ by $0.2 \mathrm{kV}$ step and the PD distance is gradually increased from $1.5 \mathrm{~cm}$ to $3.5 \mathrm{~cm}$. The experimental data (starting discharge voltage vs. extinction voltage) is shown in Tables $\mathbf{1}$ and $\mathbf{2}$. Furthermore, with the study of solid insulation of power transformer, the source voltage is gradually increased from 4.4 to $7.8 \mathrm{kV}$ by $0.2 \mathrm{kV}$ step and the PD distance is gradually increased from $1.5 \mathrm{~cm}$ to $3.5 \mathrm{~cm}$. The experimental data (starting discharge voltage $V S$. extinction voltage) is shown in Table 3 .

Table 1. PD data on point discharge in transformer oil (P1).

\begin{tabular}{|c|c|c|}
\hline Distance/cm & Starting Voltage $/ \mathbf{k V}$ & Extinction Voltage $/ \mathbf{k V}$ \\
\hline \hline 3.5 & 5.8 & 5.0 \\
2.4 & 5.0 & 4.6 \\
1.0 & 4.5 & 4.1 \\
0.5 & 3.0 & 2.4 \\
\hline
\end{tabular}

Table 2. PD Data on surface discharge in transformer oil (P3).

\begin{tabular}{|c|c|c|}
\hline Distance/cm & Starting Voltage/kV & Extinction Voltage $/ \mathbf{k V}$ \\
\hline \hline 3.5 & $\mathbf{7 . 3}$ & $\mathbf{6 . 7}$ \\
2.5 & $\mathbf{6 . 8}$ & $\mathbf{6 . 2}$ \\
1.5 & $\mathbf{6 . 3}$ & $\mathbf{5 . 7}$ \\
\hline
\end{tabular}

Table 3. PD Data on solid insulation of power transformer (P2).

\begin{tabular}{|c|c|c|}
\hline $\begin{array}{c}\text { Distance } \\
/ \mathrm{cm}\end{array}$ & $\begin{array}{c}\text { Starting voltage } \\
/ \mathrm{kV}\end{array}$ & $\begin{array}{c}\text { Extinction voltage } \\
/ \mathrm{kV}\end{array}$ \\
\hline \hline 3.5 & 7.8 & 7.4 \\
2.5 & 6.3 & 5.8 \\
1.5 & 4.4 & 3.9 \\
\hline
\end{tabular}

And the PD pulse maps are shown in Fig. (4) (point discharge) and Fig. (5) (surface discharge). As can be seen from the pulse map, the initial pulses are at the point of $90^{\circ}$ and $270^{\circ}$. With the increase of source voltage, the number of PD pulses is increased and the PD pulse span are enlarged.


Fig. (4). Point discharge PD pulse map under the voltage (3.0kV $v s$. $5.8 \mathrm{kV})$.
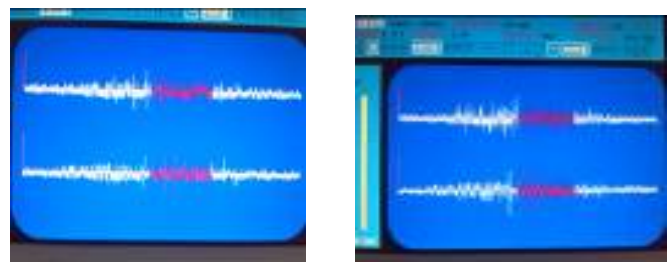

Fig. (5). Surface discharge PD pulse map under the voltage $(6.3 \mathrm{kV}$ vs. $7.3 \mathrm{kV})$

Comparing with Fig. (4) with Fig. (5), there are some difference found between point discharge PD pulse map and 
Initialization of Particle Swarm



Fig. (6). Flow chart based on PSD-PSO algorithm.

surface discharge PD pulse map at the viewpoint of statistical analysis. In order to have a good weight distribution of $\mathrm{PSO}$, the power spectrum density (PSD) is introduced in this paper.

\subsection{Power Spectrum Density Analysis}

PSD analysis is the method which indicates the relation between the power change and the frequency variation. The most part of the PSD is the calculation of spectral density function. With the help of PAD analysis, statistical operator, pulse waveform characteristics, and fractal characteristics in 2 dimensions or 3 dimensions can be considered. As can be seen in Equation 1, the frequency of $\mathrm{PD}$ and the maximum $\mathrm{PD}$ value can be calculated by the different windows spectral density functions (such as Boxcar data sampling, Hamming data sampling and Blackman data sampling etc.).

$\int_{-\infty}^{+\infty}|S(t)|^{2} d t=\int_{-\infty}^{+\infty}|S(f)|^{2} d f$

\section{PARTICAL DISCHARGE PATTERN RECOG- NITION}

\subsection{Data Pre-Processing}

With the help of PD monitor (JFD251) and 50 times PD experiments on $0.4 \mathrm{kV} / 10 \mathrm{kV}$ power transformers, three types of PD models $\Delta \mathrm{Q}-\mathrm{U}$ mode data can be obtained. As a PD data sample $x_{i}=\left[x_{1}, x_{2}, x_{3}, \cdots, x_{k}\right]^{T}$, where $\mathrm{k}$ is the sampling number in the unit time. In this paper, source voltage (in $\mathrm{P} 1$ )is gradually increased from 3.0 to $5.8 \mathrm{kV}$ by $0.2 \mathrm{kV}$ each step, so the $\mathrm{k} 1=(5.8-2.0) / 0.2=19$.

In the same way, $\mathrm{k} 2($ in $\mathrm{P} 2)=(7.8-4.4) / 0.2=17$, and $\mathrm{k} 3$ (in $\mathrm{P} 3)=(7.3-6.3) / 0.2=5$. Because of the difference among the parameters $\mathrm{k} 1, \mathrm{k} 2$ and $\mathrm{k} 3$, so normalization process is very essential in PD data pre-processing. As is shown in equation 2, 120 samples can be obtained in the experiments with the three modes (P1, P2 and P3).

$$
x(t)_{u n}=\frac{\max \{x(i)\}-x(t)}{\max \{x(i)\}-\min \{x(i)\}}
$$

In order to have a good pattern recognition result, based on 10-fold, cross-validation is proposed. Moreover, there are 60 classification samples and 40 test samples. In this way, we can get a sample matrix $X_{\text {un }}(120 * 60)$.

\subsection{Pattern Discovery Flow Chart}

In order to have a good and fast pattern recognition result on the classification modes of P1, P2 and P3, there are two testing parts in the $\mathrm{PD}$ pattern recognition: data-training stage and data-testing stage. The flow chart based on PSDPSO algorithm is shown in Fig. (6). 


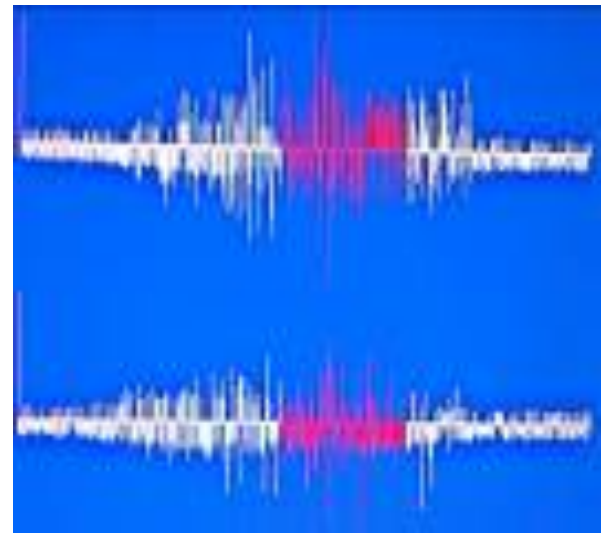

Point discharge PD pulse 3-D image



Point discharge PD pulse 2-D image



Surface discharge PD pulse 3-D image



Surface discharge PD pulse 2-D gray image

Fig. (7). Gray-conversion on PD Images.


Fig. (8). Power spectrums of different PD propagation characteristics.

\subsection{Pattern Analysis}

In order to get fast and accurate pattern recognition results, the 3-D colourful PD images are converted to the 2-D gray PD images, as can be seen in Fig. (7). With the help of PSD method, the power spectrums of different PD propagation characteristics can be obtained in Fig. (8).

\subsection{Identification Results}

With help of Matlab 7.0, the PD propagation characteristics identification results and PD pattern samples (3 types P1, P2 and P3, 512 data in one type) are displayed in Table 4. And pattern recognition results by $\mathrm{BP}$ algorithm with the same computer (with CPU of Celeron $400 \mathrm{MHz}$ ) are also shown in Table $\mathbf{5}$.

Table 4. Results of pattern recognition by PSD-PSO algorithm.

\begin{tabular}{|c|c|c|c|c|c|}
\hline \multirow{2}{*}{$\begin{array}{c}\text { PD } \\
\text { Types }\end{array}$} & \multicolumn{3}{|c|}{ Results of Pattern } & \multirow{2}{*}{ Tims/ms } & Correct \\
Rate \\
\cline { 2 - 4 } & P1 & P2 & P3 & & \\
\hline \hline P1 & 490 & 10 & 12 & 35 & $95.7 \%$ \\
\hline P2 & 8 & 503 & 1 & 45 & $98.2 \%$ \\
\hline P3 & 5 & 10 & 495 & 37 & $96.7 \%$ \\
\hline \multicolumn{7}{c}{ Average } & & 39 & $96.9 \%$ \\
\hline
\end{tabular}

Table 5. Results of pattern recognition by BP algorithm.

\begin{tabular}{|c|c|c|c|c|c|}
\hline \multirow{2}{*}{$\begin{array}{c}\text { PD } \\
\text { Types }\end{array}$} & \multicolumn{3}{|c|}{$\begin{array}{c}\text { Results of Pattern } \\
\text { Recognition }\end{array}$} & \multirow{2}{*}{ Time/ms } & \multirow{2}{*}{$\begin{array}{c}\text { Correct } \\
\text { Rate }\end{array}$} \\
\hline & P1 & $\mathbf{P 2}$ & P3 & & \\
\hline P1 & 438 & 25 & 49 & 203 & $85.5 \%$ \\
\hline P2 & 33 & 427 & 52 & 173 & $83.4 \%$ \\
\hline P3 & 23 & 50 & 439 & 190 & $85.7 \%$ \\
\hline \multicolumn{4}{|c|}{ Average } & 188.7 & $84.9 \%$ \\
\hline
\end{tabular}


As can be seen from Tables $\mathbf{4}$ and 5, compared with the BP ANN network, PSD-PSO algorithm can improve the accuracy (from $84.9 \%$ to $96.9 \%$ ) and the real-time performance (39ms VS. $188.7 \mathrm{~ms}$ ) of fault diagnosis in power transformers.

\section{CONCLUSION}

In this paper, partial discharge comprehensive fault decision of $0.4 \mathrm{KV} / 10 \mathrm{KV}$ power transformer based on PSD-PSO algorithm is discussed. The simulation results show that the improved PSD-PSO algorithm has the advantages of better classification effect (from $84.9 \%$ to $96.9 \%$ ), being easy to realize and better real-time performance (39ms VS. 188.7 $\mathrm{ms}$ ) of fault diagnosis in power transformers. And the simulation results also demonstrate the effectiveness of the improved method. On the other hand, the PSD-PSO method can meet the requirements of comprehensive fault decision on other power equipment such as power switchgears and porcelain insulators etc.

\section{CONFLICT OF INTEREST}

The authors confirm that this article content has no conflict of interest.

\section{ACKNOWLEDGEMENTS}

The Project is Supported by Fujian Provincial Major Scientific and Technological Projects under grant 2014H6028, Scientific Research Items of XMUT under grant
XYK201401, XMUT Initializing Foundation under grant YKJ12010R, and funding (type A) (funding number: JA12253) from the Fujian Education; Department. Xiamen Science and Technology Plan Project (3502Z20123043).

\section{REFERENCES}

[1] S. Shukla, S. Mishra, and B. Singh, "Empirical-mode decomposition with hilbert transform for power-quality assessment," IEEE Transactions on Power Delivery, vol. 24, no. 4, pp. 2159-2165, 2009.

[2] P.E. Sutherland, and T.A. Short, "Power quality assessment of distributed generator grounding method," IEEE Transactions on Industry Applications, vol. 45, no. 1, pp. 303-309, 2009.

[3] M. Karimi-Ghartemani, and M. R. Iravani, "Measurement of harmonics/inter-harmonics of time-varying frequencies," IEEE Transactions on Power Delivery, vol. 20, no. 1, pp. 23-31, 2005.

[4] X. B. Bian, and A. D. Bandrauk, "Multichannel molecular highorder harmonic generation from asymmetric diatomic molecules,' Physical Review Letters, vol. 105, no. 9, pp. 93903, 2010.

[5] N. Bianchi, S. Bolognani, M.D. Pre, G. Grezzani, "Design considerations for fractional-slot winding configurations of synchronous machines," IEEE Transactions on Industry Applications, vol. 42, no. 4, pp. 997-1006, 2006.

[6] IEC270, Partial Discharge Measurements, High-Voltage Test Techniques 2000.

[7] J. Sugier, "Computational methods for adaptation of markov models to requested maintenance policies," Computer Modelling and New Technologies, vol. 17, no.1, pp. 14-24, 2013

[8] R. Ding, C. Ma, Y. Zhao, Y. Lu, and J. Liu, “Anti-synchronization of a class of fractional-order chaotic system with uncertain parameters," Computer Modeling and New Technologies, vol. 18, no. 11, pp. 109-112, 2014.

[9] D. M. Divan, S. Bhattacharya, and B. Baneriee, "Synchronous frame harmonic isolator using acrtive series filter," In: Proceeding Europe Power Electronics Conference, pp. 3030-3035, 1991.

(C) Zhenhua et al.; Licensee Bentham Open.

This is an open access article licensed under the terms of the (https://creativecommons.org/licenses/by/4.0/legalcode), which permits unrestricted, non-commercial use, distribution and reproduction in any medium, provided the work is properly cited. 